Check for updates

Cite this: RSC Adv., 2018, 8, 24906

\title{
Preparation of polymethacrylate monolith modified with cysteine for the determination of Cr(III) ions
}

\begin{abstract}
Dan Liu, (D)* Junli Pan, Jianghong Tang and Ning Lian
In this study, a simple and rapid polymer monolith microextraction procedure was developed for the determination of $\mathrm{Cr}(\mathrm{II})$ ions by inductively coupled plasma-atomic emission spectrometry. A monolithic column modified with cysteine was synthesized and characterized by scanning electron microscopy, Fourier-transform infrared spectroscopy, X-ray photoelectron spectroscopy, thermal gravimetric analysis, specific surface area analysis and pore size distribution analysis. The influences of analytical parameters such as sample $\mathrm{pH}$, adsorption time, eluent type, and coexisting ions were examined. The limit of detection (LOD) and limit of quantification (LOQ) for $\mathrm{Cr}\left(\right.$ III) ions were $0.005 \mu \mathrm{g} \mathrm{mL}^{-1}$ and $0.017 \mu \mathrm{g} \mathrm{mL}^{-1}$, and the relative standard deviation (RSD) was $7.4 \%(n=5)$. The prepared cysteine functionalized monolithic column displayed good enrichment capacity and was successfully applied to the determination of $\mathrm{Cr}(\mathrm{III})$ ions in real samples.
\end{abstract}

Received 9th February 2018

Accepted 29th June 2018

DOI: $10.1039 / c 8 r a 01287 c$

rsc.li/rsc-advances classical time consuming approaches which utilize large volumes of solvents and offer unsatisfactory recoveries. ${ }^{21}$

In order to obtain higher selectivity and sensitivity, the above-mentioned analytical techniques have been coupled with extraction and preconcentration methods such as liquidliquid extraction (LLE), ${ }^{\mathbf{1 3 , 2 2 , 2 3}}$ solid-phase extraction (SPE), ${ }^{\mathbf{1 , 4 , 2 4}}$ solid phase microextraction (SPME), ${ }^{15,25}$ magnetic solid phase extraction (MSPE), ${ }^{19}$ cloud point extraction (CPE), ${ }^{26,27}$ and electromembrane extraction (EE). ${ }^{28,29}$ Although each procedure provides its own advantages, most of them suffer from different disadvantages such as large amounts of organic solvents, time consumption, tediousness or low enrichment factor. ${ }^{15}$ To overcome these disadvantages, chemists have tried to develop environment-friendly and more efficient extraction methods such as polymer monolith microextraction (PMME). ${ }^{30}$

PMME, based on capillary monolithic column, is an effective method to preconcentrate trace analytes from environmental and biological samples before the analysis step. ${ }^{31}$ However, some modified techniques are conducted due to monolithic column does not provide satisfactory selectivity for some metal ions. Cysteine is a sulfur-containing amino acid with three functional groups $\left(-\mathrm{SH},-\mathrm{NH}_{2},-\mathrm{COOH}\right)$, which exhibit fascinating properties, such as nucleophilicity, redox activity, and metal-binding affinity. ${ }^{32}$ Electroactive mercapto group have a strong tendency to coordinate with heavy metal ions through Lewis acid-based interaction. ${ }^{21}$ Muralikrishna et al. reported a L-cysteine functionalized graphene oxide for simultaneous electrochemical determination of four heavy metal ions with low detection limits. ${ }^{33}$ Both $-\mathrm{SH}$ and $-\mathrm{NH}_{2}$ functional groups could be used to form cross-linked networks 
with epoxy groups to provide the chemical stability and surface property. ${ }^{34}$ Moreover, $-\mathrm{NH}_{2},-\mathrm{SH}$, and $-\mathrm{COOH}$ groups could also provide a good bio-compatibility and solubility, and participated well in the aqueous removal of metal ions by forming various complexes. ${ }^{35-37}$ Therefore, the introduction of cysteine will be a good choice to meet the needs of improving the stability of materials and enhancing the sensitivity and selectivity of adsorption materials toward heavy metal ions.

In this paper, L-cysteine functionalized polymer monolithic column (L-cys@poly(GMA-MAA-EDMA)) was synthesized, characterized, and successfully applied for the preconcentration and determination of $\mathrm{Cr}(\mathrm{III})$ ions. Extraction conditions affecting the extraction efficiency were investigated and optimized. To demonstrate the validation of the developed method, the detection limit, anti-interference, and precision were also studied in detail.

\section{Experimental section}

\subsection{Chemicals and instruments}

Glycidyl methacrylate (GMA), ethylene dimethacrylate (EDMA), $\alpha$-methacrylic acid (MAA), $\gamma$-methacryloxypropyltrimethoxysilane ( $\gamma$-MAPS), cyclohexanol, dodecanol, azobisisobutyronitrile (AIBN), and L-cysteine (L-cys) were purchased from Macklin Reagent (Shanghai, China). Methanol, sodium dihydrogen phosphate $\left(\mathrm{NaH}_{2} \mathrm{PO}_{4}\right)$, sodium hydrogen phosphate $\left(\mathrm{Na}_{2} \mathrm{HPO}_{4}\right)$, trifluoroacetic acid (TFA), and acetone were obtained from Jiangsu Qiangsheng Chemical Co., Ltd. (Changshu, China). Chromic nitrate $\left(\mathrm{Cr}\left(\mathrm{NO}_{3}\right)_{3}\right)$ were purchased from Chinese Chemical Reagent Co., Ltd (Shanghai, China).

Fused-silica capillaries $(530 \mu \mathrm{m}$ id $\times 690 \mu \mathrm{m}$ od $)$ were purchased from Hebei Yongnian Optical Conductive Fiber Plant (Handan, China). The extraction driving force was provided by a GenieTouch syringe pump from Kent Scientific (San Francisco, USA). An H1650-W centrifuge (Hunan Xiangyi, China) was used for centrifuging. A pHS-3E digital $\mathrm{pH}$ meter (Shanghai INESA Electron Co., Ltd., China) was used for $\mathrm{pH}$ measurements of sample solutions.

An Optima 2100DV inductively coupled plasma-atomic emission spectrometry (Perkin Elmer Instruments, Shelton, CT, USA) was used. The operation conditions and the wavelength of emission lines were summarized in Table 1. Scanning electron microscope (SEM) images were recorded on a S-

Table 1 Operating conditions of the ICP-AES instrument

\section{Parameters}

Incident power $(\mathrm{W})$

Plasma gas (Ar) flow rate $\left(\mathrm{L} \mathrm{min}^{-1}\right)$

Auxiliary gas (Ar) flow rate $\left(\mathrm{L} \mathrm{min}^{-1}\right)$

Nebulizer gas (Ar) flow rate $\left(\mathrm{L} \mathrm{min}^{-1}\right)$

Observation height (mm)

Integration time (s)

Solution pump rate $\left(\mathrm{mL} \mathrm{min}^{-1}\right)$

Wavelength (nm)
$3400 \mathrm{~N}$ analyzer (JEOL Company, Japan). X-ray photoelectron spectroscopy (XPS) data were obtained with an Escalab 250Xi electron spectrometer (Thermo Fisher Scientific, UK). Fourier transform infrared spectra (FT-IR) were performed using IR200 FT-IR spectrometer (Thermo Corporation, USA). Thermal gravimetric analysis (TGA) were carried out on a Q500 apparatus (TA, USA) from 30 to $800{ }^{\circ} \mathrm{C}$ with a heating rate of $10{ }^{\circ} \mathrm{C} \mathrm{min}{ }^{-1}$ under air atmosphere. Specific surface area values were determined by the Brunauer-Emmett-Teller (BET) method and the pore size distribution was evaluated from the desorption branches of isotherms based on the Barrett-Joyner-Halenda (BJH) model.

\subsection{Synthesis of poly(GMA-MAA-EDMA) and $\mathrm{L}^{-}$ cys@poly(GMA-MAA-EDMA) monolithic columns}

Prior to the polymerization, the fused-silica capillary was vinylized with $\gamma$-MAPS to enable covalent attachment of the monolithic column according to our published procedure. ${ }^{38}$ Subsequently, the polymerization mixture for preparing the poly(GMA-MAA-EDMA) monolith, consisting of monomer (160 mg GMA + $40 \mathrm{mg}$ MAA), cross-linker (123 mg EDMA), porogen (900 mg cyclohexanol $+100 \mathrm{mg}$ dodecanol), and initiator (4 mg AIBN), was degassed by ultrasonication for about $30 \mathrm{~min}$. Then the homogeneous solution was filled into the pretreated capillary and sealed at both ends with rubber stoppers. The polymerization was initiated at $50{ }^{\circ} \mathrm{C}$ for $24 \mathrm{~h}$. Finally, the prepared capillary was washed with methanol to remove the unreacted components.

L-cys@poly(GMA-MAA-EDMA) monolithic column was prepared as follows. $2 \mu \mathrm{g} \mathrm{mL} \mathrm{mL}^{-1}$ L-cys aqueous solution was pumped through the poly(GMA-MAA-EDMA) monolith at a flow rate of $0.005 \mathrm{~mL} \mathrm{~min}^{-1}$ for $3 \mathrm{~h}$. The column was sealed with rubber septum at both ends, and placed in an oven for $4 \mathrm{~h}$ at $70{ }^{\circ} \mathrm{C}$. The column was rinsed with water to remove excess reagents and then obtained L-cys@poly(GMA-MAA-EDMA) monolithic column.

\subsection{Standard solutions and separation conditions}

The stock solutions were prepared for $\mathrm{Cr}(\mathrm{III})$ ions by dissolving the appropriate amount of $\mathrm{Cr}\left(\mathrm{NO}_{3}\right)_{3}$ in concentrated $\mathrm{HNO}_{3}$. Test solutions of $\mathrm{Cr}(\mathrm{III})$ ions were prepared by appropriate dilution of the prepared stock standard solutions. Deionized water was used for the preparation of solutions.

The extraction procedure included preconditioning, sampling, evacuation, and desorption. Prior to extraction, $0.3 \mathrm{~mL}$ methanol was passed through the polymer monolithic column for $3 \mathrm{~min}$ at $0.1 \mathrm{~mL} \mathrm{~min}^{-1}$, and then the sample solution was injected to realize the adsorption at $0.02 \mathrm{~mL} \mathrm{~min}^{-1}$ for 15 min. Subsequently, an empty and clean syringe was employed for driving out the residual solution in the polymer monolithic column. For the desorption step, $\mathrm{Cr}(\mathrm{III})$ ions adsorbed on the monolithic column were eluted with $0.05 \mathrm{~mL}$ $1.5 \mathrm{~mol} \mathrm{~L}^{-1} \mathrm{HNO}_{3}$ at $0.02 \mathrm{~mL} \mathrm{~min}{ }^{-1}$, and the eluent was collected into a vial for ICP-AES analysis. 


\section{Results and discussion}

\subsection{Characteristics of L-cys@poly(GMA-MAA-EDMA) monolith}

The amount of L-cys was investigated by the perviousness of the monolith, which was determined by flow rate, i.e., the volume was determined when the solution passed through the monolith within a certain time. An optimized polymer monolith should afford good perviousness and enrichment performance. Based on preliminary results, we found that the excessive amount of L-cys in water solution was passed through flow resistance and poor perviousness. Finally, $2 \mu \mathrm{g} \mathrm{mL}{ }^{-1} \mathrm{~L}$-cys was selected for the monolith in subsequent experiments. SEM images were usually used to reflect the morphology feature of monolithic materials. SEM images (Fig. 1) clearly indicated that the L-cys@poly(GMA-MAA-EDMA) monolith was composed of a heterogeneous surface, fully filled in the capillary having bicontinuous structure and through-pores, and tightly anchored to the capillary wall. ${ }^{39}$ That guaranteed fast dynamic transport and high efficient enrichment in applications.

FT-IR spectra of L-cys@poly(GMA-MAA-EDMA) and poly(GMA-MAA-EDMA) monoliths were illustrated in Fig. 2. The characteristic bands at $1730 \mathrm{~cm}^{-1}$ which was due to $\mathrm{C}=\mathrm{O}$ stretch of the monolith. ${ }^{40}$ The broad vibration centered at $3500 \mathrm{~cm}^{-1}$ was assigned to $\mathrm{O}-\mathrm{H}$ and/or N-H stretching vibrations. ${ }^{41}$ In addition, the bands at $2980 \mathrm{~cm}^{-1}$ corresponded to $\mathrm{C}-\mathrm{H}$ stretching vibration. The characteristic absorption peaks at $1060 \mathrm{~cm}^{-1}$ to $\mathrm{C}-\mathrm{N}, 1640 \mathrm{~cm}^{-1}$ to $\mathrm{C}=\mathrm{C}$, and $2550 \mathrm{~cm}^{-1}$ to $\mathrm{S}-\mathrm{H}$
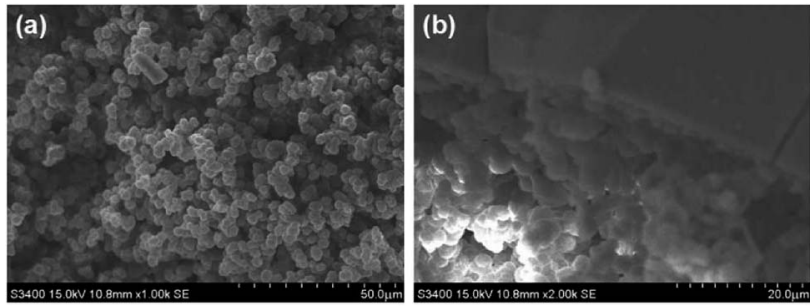

Fig. 1 SEM images of L-cys apoly(GMA-MAA-EDMA) monolith.

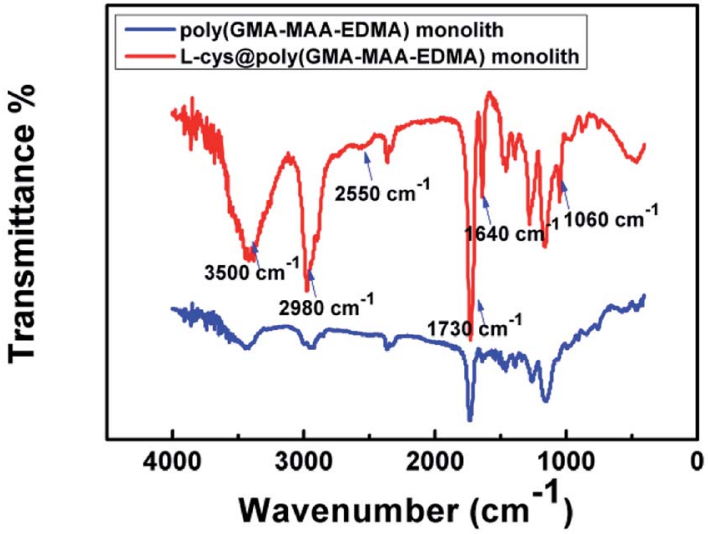

Fig. 2 FT-IR spectra of L-cysapoly(GMA-MAA-EDMA) and poly(GMAMAA-EDMA) monoliths.

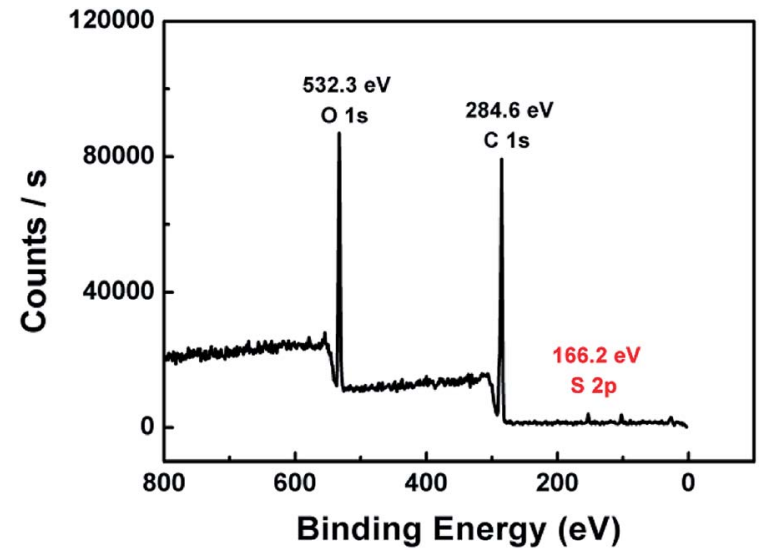

Fig. 3 XPS spectra for O, C, and S element of L-cys@poly(GMA-MAAEDMA) monolith.

stretching vibrations. ${ }^{42}$ The above FT-IR results demonstrated that L-cys was introduced into poly(GMA-MAA-EDMA) monolith.

The L-cys@poly(GMA-MAA-EDMA) monolith was characterized by XPS in order to explore the $\mathrm{S}$ composition of the column surface. As shown in Fig. 3, typical O1s, C1s, and S2p XPS spectra of the monolith were shown at 532.3, 284.6, and $166.2 \mathrm{eV}$, respectively. Notably, the existence of $\mathrm{S}$ elements indicated that poly(GMA-MAA-EDMA) monolith was bonded with L-cys successfully.

Thermal properties of poly(GMA-MAA-EDMA) and Lcys@poly(GMA-MAA-EDMA) monoliths were analyzed by TGA measurement, which were carried out under $\mathrm{N}_{2}$ with a heating rate of $10^{\circ} \mathrm{C} \mathrm{min}^{-1}$ over the temperature range of $30-800{ }^{\circ} \mathrm{C}$. As shown in Fig. 4, the degradation curve of the prepared $\mathrm{L}^{-}$ cys@poly(GMA-MAA-EDMA) monolith materials indicated a three-stage process. The first weight loss existed in the range of $30-100{ }^{\circ} \mathrm{C}$ because of the evaporation of the adsorbed water and the decomposition of labile oxygen. Furthermore, it could be observed that the residual mass of $5.5 \%$ might be due to the L-cys decomposition of L-cys@poly(GMA-MAA-EDMA) monolith. The third weight loss in the range of $360-450{ }^{\circ} \mathrm{C}$ might be corresponding to the monolithic material. TGA curve tended to

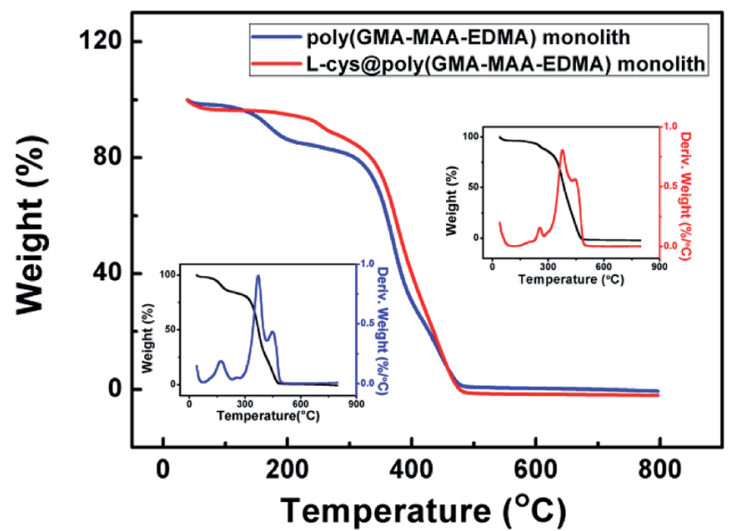

Fig. 4 TGA curves of poly(GMA-MAA-EDMA) and L-cysapoly(GMAMAA-EDMA) monoliths. 

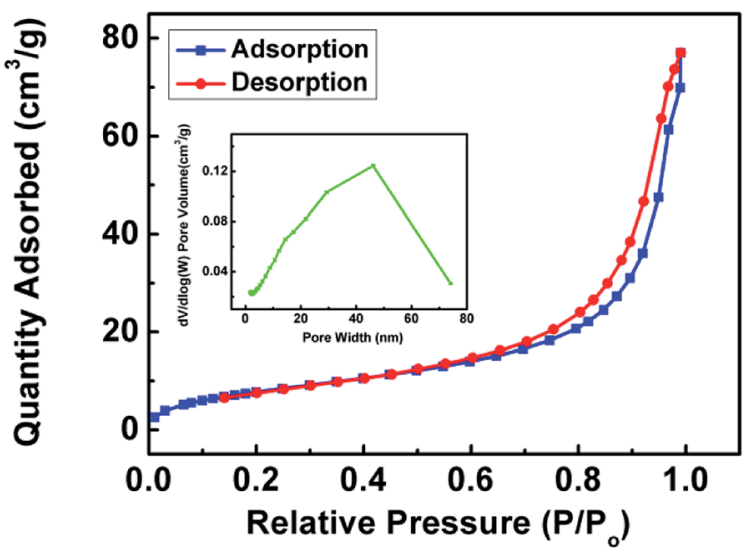

Fig. $5 \quad \mathrm{~N}_{2}$ adsorption-desorption isotherm and pore size distribution plot (inset) of L-cys@poly(GMA-MAA-EDMA) monolith.

be constant when the temperature was higher than $450{ }^{\circ} \mathrm{C}$, indicated the complete decomposition of the monolithic material.

The specific surface area and pore size distribution of L-cys@poly(GMA-MAA-EDMA) monolith was investigated with $\mathrm{N}_{2}$ adsorption-desorption analysis. As shown in Fig. 5, the hysteresis in the adsorption-desorption isotherm of the monolith implied the presence of mesoporosity. ${ }^{43}$ The hysteresis loop was associated with the capillary condensation taking place in mesopores. ${ }^{\mathbf{4 4}}$ Furthermore, the BET specific surface area of monolith was calculated $30.31 \mathrm{~m}^{2} \mathrm{~g}^{-1}$. The above results showed that the prepared L-cys@poly(GMA-MAA-EDMA) monolith could provide relatively larger surface area and more accessibilities of reactive sites, which might improve the loading capacity.

\subsection{Optimization of PMME conditions}

Various parameters affecting extraction efficiency, including sample $\mathrm{pH}$, adsorption time, and eluent type were investigated. The intensity of $\mathrm{Cr}(\mathrm{III})$ ions were used to evaluate the extraction efficiency under various experimental conditions.

To achieve efficient desorption of $\mathrm{Cr}(\mathrm{III})$ ions from monolith, various eluent solvents, including $1.5 \mathrm{~mol} \mathrm{~L} \mathrm{~L}^{-1} \mathrm{HNO}_{3}$, $1.0 \mathrm{~mol} \mathrm{~L}^{-1} \mathrm{HNO}_{3}$, and 1\% TFA aqueous solution were adopted to investigate the desorption efficiency at the flow rate of 0.03 $\mathrm{mL} \mathrm{min}^{-1}$, as shown in Fig. 6(a). The intensity using $1.5 \mathrm{~mol} \mathrm{~L}^{-1}$ $\mathrm{HNO}_{3}$ as the elution solvent was slightly higher than those of the others. However, $\mathrm{HNO}_{3}$ with too high concentration may damage the monolithic column. Therefore, $1.5 \mathrm{~mol} \mathrm{~L}^{-1} \mathrm{HNO}_{3}$ was chosen as the eluent in this experiment.

To investigate the extraction ability of L-cys@poly(GMA-MAAEDMA) monolith for $\mathrm{Cr}(\mathrm{III})$ ions, the extraction equilibrium profiles were constructed by increasing the adsorption time in the range of 5-30 min at a constant flow rate of $0.02 \mathrm{~mL} \mathrm{~min}^{-1}$. Results were demonstrated in Fig. 6(b), illustrated that the intensity showed a significant increasing tendency and the extraction equilibrium did not reach a maximum. Taking the time of experiment into consideration, $15 \mathrm{~min}$ was selected for further adsorption experiments.
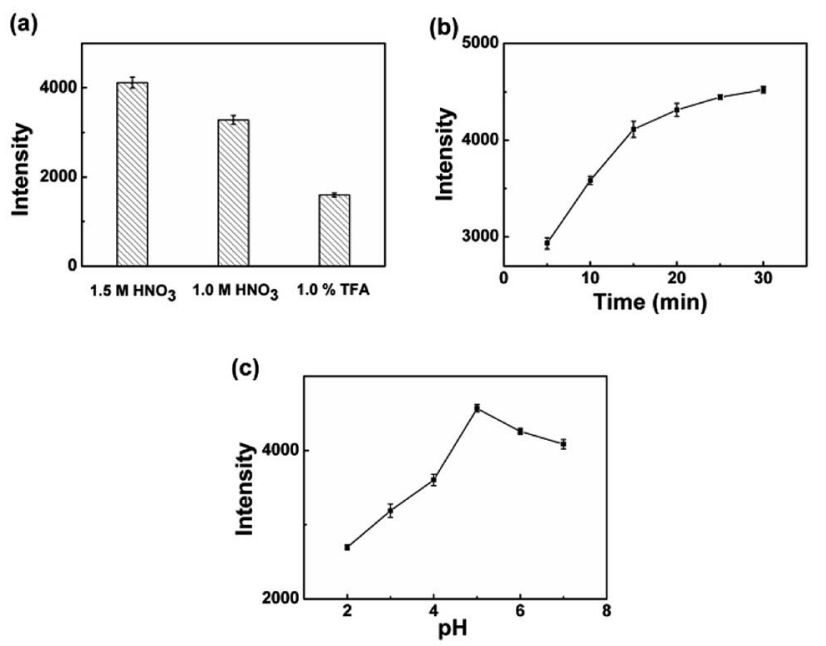

Fig. 6 Effects of (a) type of eluent; (b) adsorption time; (c) pH.

Table 2 Effect of coexisting ions

\begin{tabular}{|c|c|}
\hline $\begin{array}{l}\text { Coexisting } \\
\text { ions }\end{array}$ & $\begin{array}{l}\text { Tolerance limit/ } \mu \mathrm{g} \\
\mathrm{mL}^{-1}\end{array}$ \\
\hline $\mathrm{Na}^{+}$ & 1000 \\
\hline $\mathrm{Mg}^{2+}$ & 1000 \\
\hline $\mathrm{Fe}^{3+}$ & 100 \\
\hline $\mathrm{Zn}^{2+}$ & 100 \\
\hline $\mathrm{Ni}^{2+}$ & 500 \\
\hline $\mathrm{Al}^{3+}$ & 500 \\
\hline $\mathrm{SO}_{4}{ }^{2-}$ & 1000 \\
\hline $\mathrm{Cl}^{-}$ & 1000 \\
\hline
\end{tabular}

Sample pH plays an important role in the separation and preconcentration of $\mathrm{Cr}$ (III) ions because $\mathrm{pH}$ value not only decides the form of active sites on the polymer monolithic column surface but also influences the adsorption capacity. The effect of $\mathrm{pH}$ on the adsorption of $\mathrm{Cr}(\mathrm{III})$ ions was investigated in the range of 2-7. As can be seen from Fig. 6(c), the quantitative adsorption of $\mathrm{Cr}$ (III) ions were increased with the increase of $\mathrm{pH}$ values from 2 to 5 and the intensity reached maximum at nearby $\mathrm{pH}$ 5.0. The above results could be explained by the different adsorption mechanism of $\mathrm{Cr}$ (III) ions on L-cys@poly(GMA-MAA-EDMA) monolith. The surface charge on monolith turned to positively charged in acidic aqueous solution, that should result in electrostatic repulsion with potentially $\mathrm{Cr}$ (III) ions which was still positively charged. ${ }^{33}$ Thiol-functionalized monolith could coordinate with heavy metal ions due to the specific property of soft base at the same time. $^{45}$ Once $\mathrm{pH}$ increased, the concentration of hydrated hydrogen ions $\left(\mathrm{H}_{3} \mathrm{O}^{+}\right)$would decrease, resulting the adsorption of $\mathrm{Cr}(\mathrm{III})$ ions got increased. Furthermore, the amino group and carboxyl group were deprotonated, ${ }^{\mathbf{1}}$ which maybe coordinate with $\mathrm{Cr}$ (III) ions through nitrogen atoms and oxygen atoms or sulfur atoms and oxygen atoms of L-cys@poly(GMA-MAA-EDMA) monolith.,25 
Table 3 Analytical results of $\mathrm{Cr}(\mathrm{III})$ ions in water samples (mean $\pm \mathrm{sd}, n$ $=3)$

\begin{tabular}{llll}
\hline Sample & Added $\left(\mu \mathrm{g} \mathrm{mL}^{-1}\right)$ & Found $\left(\mu \mathrm{g} \mathrm{mL}{ }^{-1}\right)$ & Recovery $(\%)$ \\
\hline S1 & - & n.d. & - \\
& 0.05 & $0.051 \pm 0.002$ & $102.0 \%$ \\
& 0.1 & $0.094 \pm 0.003$ & $94.0 \%$ \\
S2 & 1.0 & $0.817 \pm 0.014$ & $81.7 \%$ \\
& - & $0.006 \pm 0.001$ & - \\
& 0.05 & $0.049 \pm 0.003$ & $86.0 \%$ \\
S3 & 0.1 & $0.113 \pm 0.005$ & $107.0 \%$ \\
& 1.0 & $0.839 \pm 0.033$ & $83.9 \%$ \\
& - & n.d. & - \\
& 0.05 & $0.054 \pm 0.007$ & $108.0 \%$ \\
& 0.1 & $0.097 \pm 0.005$ & $97.0 \%$ \\
& 1.0 & $0.857 \pm 0.030$ & $85.7 \%$
\end{tabular}

\subsection{Effect of coexisting ions}

Preconcentration methods for trace determination of metal ions can be strongly affected by the matrix constituents of the samples. To demonstrate the reliability of the developed method, quantities of prepared coexisting ions solutions were added to standard solutions containing $0.1 \mu \mathrm{g} \mathrm{mL}{ }^{-1} \mathrm{Cr}$ (III) ions according to the recommended procedure for monitoring intensities by PMME-ICP-AES. The tolerance limit of interfering

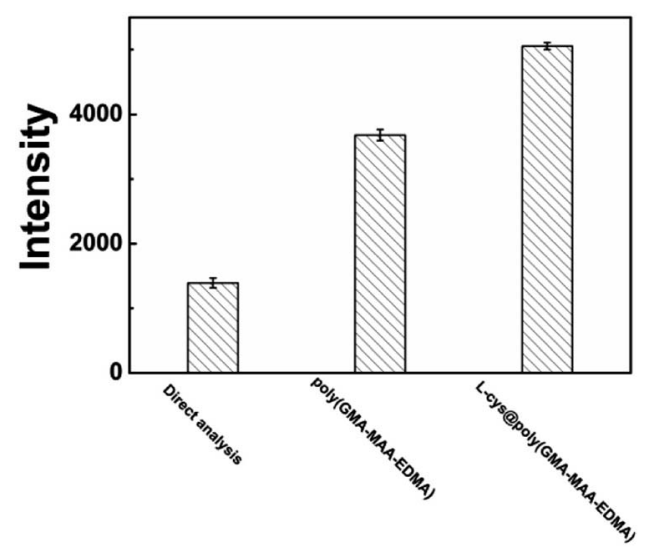

Fig. 7 Comparison of the analytical performance of $\mathrm{Cr}$ (III) ions enrichment by direct ICP-AES analysis, poly(GMA-MAA-EDMA) and Lcys@poly(GMA-MAA-EDMA) monoliths under the optimized conditions. ions was defined as a $5 \%$ decrease in signal intensity. Results in Table 2 showed that coexisting ions caused no significant interference with the determination of $0.1 \mu \mathrm{g} \mathrm{mL} \mathrm{m}^{-1}$ of $\mathrm{Cr}$ (III) ions. This is probably the result of L-cys functionalized monolith inherent selectivity that can provide the ligand groups arranged in a suitable way required for coordination of $\mathrm{Cr}$ (III) ions. The above results suggested that the PMME-ICP-AES method has great potential to be employed for the analysis of $\mathrm{Cr}$ (III) ions in various samples.

\subsection{Method validation}

Under the optimized experimental conditions, the analytical performance of the proposed method was evaluated and summarized. The developed method exhibited good linearity within the range of $0.01-5 \mu \mathrm{g} \mathrm{mL} \mathrm{L}^{-1}$. Correlation coefficients $\left(R^{2}\right)$ were always better than 0.9900 . The limit of detection (LOD) and limit of quantification (LOQ) were $0.005 \mu \mathrm{g} \mathrm{mL} \mathrm{m}^{-1}$ and $0.017 \mu \mathrm{g}$ $\mathrm{mL}^{-1}$, respectively, determined as signal to noise ratios of three and ten. The relative standard deviation (RSD) was $7.4 \%$ which was evaluated through the intensity of standard solutions using five replicates.

To evaluate the reliability of the present method for extraction and preconcentration of $\mathrm{Cr}(\mathrm{III})$ ions from real samples, some water samples were spiked with standard solutions of $\mathrm{Cr}$ (III) ions at three concentration levels, Level 1 $\left(0.05 \mu \mathrm{g} \mathrm{mL}{ }^{-1}\right)$, Level $2\left(0.1 \mu \mathrm{g} \mathrm{mL}^{-1}\right)$, and Level $3\left(1.0 \mu \mathrm{g} \mathrm{mL}^{-1}\right)$ respectively. As shown in Table 3 , the recovery values demonstrated that sufficient recoveries were achieved in the range of $81.7-108.0 \%(n=3)$. The above results showed that the accuracy, precision, stability, and recoveries of proposed method were favorable.

Comparison studies between direct ICP-AES analysis and PMME using poly(GMA-MAA-EDMA) and L-cys@poly(GMA-MAAEDMA) monoliths were performed under the optimum conditions. Definitely, as shown in Fig. 7, the intensity with L-cys@poly(GMA-MAA-EDMA) monolith was significantly higher than those with the other two methods, which may be due to the following. For poly(GMA-MAA-EDMA) monolith, the increased enrichment capacity was based on several weak interactions (such as ion-exchange interactions, electrostatic interactions, and hydrophilic interaction) between $\mathrm{Cr}(\mathrm{III})$ ions and monolith. When L-cys was introduced into the column, L-cys@poly(GMAMAA-EDMA) monolith demonstrated the preferable extraction

Table 4 Comparison of the proposed method with other methods applied for the determination of $\mathrm{Cr}(\mathrm{III})$ ions

\begin{tabular}{llll}
\hline Target ions & Method of extraction & Instrument & LOD \\
\hline Cr(III) & Plasmonic ELISA & - & $6.25 \mathrm{ng} \mathrm{mL}^{-1}$ \\
Cr(III) & SPE & ICP-OES & $0.28 \mathrm{ng}^{-1}$ \\
Cr(III) & SPE & ICP-AES & $0.25 \mathrm{ng} \mathrm{mL}^{-1}$ \\
Cr(III) & SPE & FAAS & $1.90 \mu \mathrm{mL}^{-1}$ \\
Cr(III) & SPME & GC & $22 \mathrm{ng}^{-1}$ \\
Cr(III) & CPE & FAAS & $0.08 \mu \mathrm{gL}^{-1}$ \\
Cr(III) & EE & HPLC & $5.4 \mu \mathrm{gL}^{-1}$ \\
Cr(III) & LLE & FAAS & $5.7 \mu \mathrm{gL}^{-1}$ \\
Cr(III) & PMME & ICP-AES & $0.005 \mu \mathrm{mL}^{-1}$
\end{tabular}


ability. The three functional groups $\left(-\mathrm{SH},-\mathrm{NH}_{2},-\mathrm{COOH}\right)$ of $\mathrm{L}-\mathrm{cys}$ provided a good bio-compatibility and solubility. ${ }^{35}$ Furthermore, $-\mathrm{SH},-\mathrm{NH}_{2}$, and $-\mathrm{COOH}$ functional groups could coordinate with $\mathrm{Cr}$ (III) ions through nitrogen atoms, sulfur atoms, and oxygen atoms of L-cys@poly(GMA-MAA-EDMA) monolith. ${ }^{1}$

A comparison of the developed method with other reported methods for $\mathrm{Cr}(\mathrm{III})$ ions were summarized in Table 4. Although it could not provide the best LOD level, the PMME-ICP-AES method can offer several other advantages, including that it does not require any expensive instruments and complex preparation steps and the operation is much easier. Furthermore, compared with these methods mentioned above, the solvent-free characteristics of PMME method can prevent itself from consuming a large volume of organic solvents, which makes it environmental friendly. The comparable advantages entitle the PMME technique to search further applications in other real samples.

\section{Conclusions}

In this work, the L-cysteine functionalized polymer monolithic column was successfully synthesized and characterized. Based on the novel functional polymer materials, the PMME-ICP-AES method was developed and applied for the extraction and determination of $\mathrm{Cr}$ (III) ions in water samples. Optimal extractive conditions were obtained by optimizing experimental parameters. Compared with the traditional poly(GMA-MAAEDMA) monolith, the functional monolith displayed good enrichment capacity of $\mathrm{Cr}$ (III) ions via ion-exchange, electrostatic, hydrophilic, and chelation interactions. Due to the satisfactory precision and accuracy, the present PMME-ICP-AES method proved itself to be sensitive and accurate, and has promising applications for $\mathrm{Cr}(\mathrm{III})$ ions determination in real samples.

\section{Conflicts of interest}

There are no conflicts to declare.

\section{Acknowledgements}

The financial support from Jiangsu University of Technology University is gratefully acknowledged.

\section{References}

1 W. Y. Wei, B. S. Zhao, M. He, B. B. Chen and B. Hu, RSC Adv., 2017, 7, 8504-8511.

2 S. Tiwari, M. K. Deb and B. K. Sen, Food Chem., 2017, 221, 4753.

3 F. Hernandez, F. Séby, S. Millour, L. Noël and T. Guérin, Food Chem., 2017, 214, 339-346.

4 S. Liu, H. Z. Cui, Y. L. Li, A. L. Yang, J. F. Zhang, R. Zhong, Q. Zhou, M. Lin and X. F. Hou, Microchem. J., 2017, 131, 130-136.
5 C. Z. Yao, S. T. Yu, X. Q. Li, Z. Wu, J. J. Liang, Q. Q. Fu, W. Xiao, T. J. Jiang and Y. Tang, Anal. Bioanal. Chem., 2017, 409, 1093-1100.

6 Y. Liu, P. Liang and L. Guo, Talanta, 2005, 68, 25-30.

7 M. D. Ioannidou, G. A. Zachariadis, A. N. Anthemidis and J. A. Stratis, Talanta, 2005, 65, 92-97.

8 P. Liang, T. Q. Shi, H. B. Lu, Z. C. Jiang and B. Hu, Spectrochim. Acta, Part B, 2003, 58, 1709-1714.

9 E. Yilmaz and M. Soylak, Talanta, 2016, 160, 680-685.

10 T. Dasbasi, S. Sacmaci, N. Cankaya and C. Soykan, Food Chem., 2016, 211, 68-73.

11 N. Unceta, M. Astorkia, Z. Abrego, A. Gómez-Caballero, M. A. Goicolea and R. J. Barrio, Talanta, 2016, 154, 255-262.

12 R. A. Wilson, P. A. Creed, T. Pinyayev, L. Wymer and J. T. Creed, J. AOAC Int., 2014, 97, 956-962.

13 W. Ahmad, A. S. Bashammakh, A. A. Al-Sibaai, H. Alwael and M. S. El-Shahawi, J. Mol. Liq., 2016, 224, 1242-1248.

14 M. M. Zahedi and A. Rezaei, J. Chromatogr. Sci., 2016, 54, 1851-1857.

15 T. H. Ding, H. H. Lin and C. W. Whang, J. Chromatogr. A, 2005, 1062, 49-55.

16 M. Y. Lin and C. W. Whang, J. Chromatogr. A, 2007, 1160, 336-339.

17 M. Y. Liu, L. J. Yang and L. Zhang, Talanta, 2016, 161, 288296.

18 F. A. Santos, M. Idrees, M. Silva, P. H. E. de Lima, N. Bueno, F. Nome, H. D. Fiedler and M. Pires, Desalin. Water Treat., 2013, 51, 5617-5626.

19 Z. Bahadir, V. N. Bulut, M. Hidalgo, M. Soylak and E. Marguí, Spectrochim. Acta, Part B, 2016, 115, 46-51.

20 Z. H. Li, X. J. Chang, X. J. Zou, X. B. Zhu, R. Nie, Z. Hu and R. J. Li, Anal. Chim. Acta, 2009, 632, 272-277.

21 S. F. Zhou, J. J. Wang, L. Gan, X. J. Han, H. L. Fan, L. Y. Mei, J. Huang and Y. Q. Liu, J. Alloys Compd., 2017, 721, 492-500.

22 J. Rajewski and P. Religa, J. Mol. Liq., 2016, 218, 309-315.

23 S. Sadeghi and A. Z. Moghaddam, RSC Adv., 2015, 5, 6062160629.

24 H. Wang, Y. Yao, Y. Li, S. Ma, X. Peng, J. Ou and M. Ye, Anal. Chim. Acta, 2017, 979, 58-65.

25 V. Kaur, J. S. Aulakh and A. K. Malik, Anal. Chim. Acta, 2007, 603, 44-50.

26 Z. Yıldız, G. Arslan and A. Tor, Microchim. Acta, 2011, 174, 399-405.

27 M. Ezoddin, F. Shemirani and R. Khani, Desalination, 2010, 262, 183-187.

28 Z. Tahmasebi and S. S. H. Davarani, Talanta, 2016, 161, 640646.

29 M. Safari, S. Nojavan, S. S. H. Davarani and A. MortezaNajarian, Anal. Chim. Acta, 2013, 789, 58-64.

30 D. Liu, N. Z. Song, W. Feng and Q. Jia, RSC Adv., 2016, 6, 11742-11748.

31 H. J. Zheng, J. T. Ma, W. Feng and Q. Jia, J. Chromatogr. A, 2017, 1512, 88-97.

32 T. H. Kai, N. Xia, L. Liu and J. X. Wang, RSC Adv., 2012, 2, 8729-8733. 
33 S. Muralikrishna, K. Sureshkumar, T. S. Varley, D. H. Nagaraju and T. Ramakrishnappa, $R S C A d v$., 2014, 6, 8698-8705.

34 M. Furutani, S. Sato and K. Arimitsu, J. Photopolym. Sci. Technol., 2015, 28, 737-738.

35 Y. Bagbi, A. Sarswat, D. Mohan, A. Pandey and P. R. Solanki, Sci. Rep., 2017, 7, 7672-7687.

36 J. Morton, N. Havens, A. Mugweru and A. K. Wanekaya, Electroanalysis, 2009, 21, 1597-1603.

37 L. Y. Bai, L. J. Tou, Q. Gao, P. Bose and Y. L. Zhao, Chem. Commun., 2016, 52, 13691-13694.

38 D. Liu, T. B. Zhang, Y. C. Cheng and Q. Jia, J. Sep. Sci., 2014, 37, 1826-1833.

39 S. Dixit, I. S. Lee and J. H. Park, J. Chromatogr. A, 2017, 1507, 132-140.
40 L. Yang, Z. Y. Gao, Y. L. Guo, W. C. Zhan, Y. Guo, Y. S. Wang and G. Z. Lu, Microporous Mesoporous Mater., 2014, 190, 1725.

41 H. Q. Wang, Z. Li, Q. Niu, J. T. Ma and Q. Jia, Appl. Surf. Sci., 2015, 353, 1326-1333.

42 R. K. Sajwan, Y. Bagbi, P. Sharma and P. R. Solanki, J. Lumin., 2017, 187, 126-132.

43 W. Bo, C. Wei Wei, Z. Lu Tong, L. Zhen Zhen, L. Chun Tai, C. Jing Bo and S. Chang Yu, Mater. Lett., 2017, 188, 201-204.

44 W. Ying Ke, W. Bo, W. Jin Han, R. Yu Fei, X. Chao Yang, L. Chun Tai and S. Chang Yu, J. Hazard. Mater., 2018, 344, 849-856.

45 J. M. Zhang, Z. H. Xiong, C. Li and C. S. Wu, J. Mol. Liq., 2016, 221, 43-50.

46 Z. H. Li, W. Kou, S. Wu and L. Wu, Anal. Methods, 2017, 9, 3221-3229. 